\title{
NOTES
}

\section{Synthesis of Side-Chain Polyrotaxane via Radical Polymerizations of Vinylic Pseudorotaxane Monomers Having Paraquat-type Macrocycle as a Wheel Component}

\author{
Toshikazu Takata, ${ }^{\dagger}$ Toshihide Hasegawa, ${ }^{*}$ Nobuhiro Kinara, ${ }^{*}$ and Yoshio Furusho** \\ Department of Organic and Polymeric Materials, Tokyo Institute of Technology, Ookayama, Meguro-ku, Tokyo 152-8552, Japan \\ *Department of Applied Chemistry, Osaka Prefecture University, Gakuen-cho, Sakai 599-8531, Japan \\ **Yashima Super-Structured Helix Project, JST, Moriyama-ku, Nagoya 454-5569, Japan
}

(Received May 19, 2004; Accepted August 17, 2004; Published November 15, 2004)

\begin{abstract}
KEY WORDS Side-Chain Polyrotaxane / Radical Polymerization / Pseudorotaxane Monomer / Paraquat-type Macrocycle /

[DOI 10.1295/polymj.36.927]
\end{abstract}

Interlocked molecules such as rotaxanes have a striking feature of mechanical bond. ${ }^{1}$ Because of the unconventional characteristics of the mechanical bonds, polyrotaxanes are expected to exhibit unusual viscoelastic properties such as a very large loss modulus, a low activation energy for viscous flow, and a rapid stress relaxation.,3 Applications of polyrotaxanes to a novel molecular electronic device ${ }^{4}$ and new gel systems ${ }^{5,6}$ have recently been examined.

Polyrotaxanes that have been prepared so far are roughly classified into two types, i.e., main-chain and side-chain types both of which have covalently linked polymer backbones. These polyrotaxanes are distinguished from those with topologically linked polymer backbones like poly[3]rotaxane, the first polyrotaxane bearing non-covalent main chain. ${ }^{7}$ Ritter et al. and we have recently reported versatile and efficient methods for the preparation of side-chain type polyrotaxanes by radical polymerization of vinylic pseudorotaxane monomers (Scheme 1). ${ }^{8,9}$ Ritter et al. utilized the pseudorotaxane based on a cyclodextrin-aliphatic chain motif, ${ }^{8}$ whereas our system relied on the pseudorotaxane based on a crown ether-secammonium salt motif. ${ }^{9,10}$

The pseudorotaxane monomer strategy in sidechain type polyrotaxane synthesis has been demonstrated to have some advantageous characteristics including facile and certain introduction of rotaxane units into polymers, easy synthesis of various polyrotaxanes, simple control of rotaxane unit content by copolymerization with other vinyl monomers, and modification of polymerization behavior by rotaxane formation. ${ }^{9,10}$ It is a quite important task to explore other pseudorotaxane motifs for the design of new pseudorotaxane monomers and polyrotaxanes. ${ }^{8,9}$ In this paper, we report the synthesis of side-chain polyrotaxanes by radical polymerization of vinylic pseudorotaxane monomers consisting of hydroquinolderived axle having acrylate group and a paraquattype tetracationic macrocycle.

\section{EXPERIMENTAL}

\section{General}

${ }^{1} \mathrm{H}$ and ${ }^{13} \mathrm{C}$ NMR measurements were performed on JEOL JNM-GX-270 and JNM-L-400 spectrometers in $\mathrm{CDCl}_{3}$ with tetramethylsilane as an internal reference. IR spectra were recorded on a JASCO FT-IR model 230 spectrometer. Molecular weight was estimated by GPC on a JASCO Gulliver System equipped with three polystyrene gel columns (Tosoh TSKgel $\mathrm{G} 5000 \mathrm{H}_{\mathrm{XL}}, \mathrm{G} 4000 \mathrm{H}_{\mathrm{XL}}$, and $\mathrm{G} 2500 \mathrm{H}_{\mathrm{XL}}$ ) at $35^{\circ} \mathrm{C}$, using $\mathrm{CHCl}_{3}$ as an eluent (flow rate, $1.0 \mathrm{~mL} \mathrm{~min}^{-1}$ ).

Synthesis of 3,5-Di-t-butylbenzoic Acid Ester (2). To a $\mathrm{CH}_{2} \mathrm{Cl}_{2}(4.3 \mathrm{~mL})$ solution of diol $\mathbf{1}^{11}(1.20 \mathrm{~g}$, $4.27 \mathrm{mmol})$ and $\mathrm{Et}_{3} \mathrm{~N}(3.40 \mathrm{~g}, 34.8 \mathrm{mmol})$ was added a $\mathrm{CH}_{2} \mathrm{Cl}_{2}(4.3 \mathrm{~mL})$ solution of 3,5-di-t-butylbenzoyl chloride $^{12}(1.00 \mathrm{~g}, 4.27 \mathrm{mmol})$. The mixture was stirred for $3 \mathrm{~h}$, diluted with ether $(50 \mathrm{~mL})$, washed with $2 \mathrm{M} \mathrm{HCl}(20 \mathrm{~mL} \times 2), 10 \% \mathrm{NaOHaq}(20 \mathrm{~mL} \times 1)$, water $(20 \mathrm{~mL} \times 1)$, and brine $(20 \mathrm{~mL} \times 2)$, dried $\left(\mathrm{MgSO}_{4}\right)$, and evaporated to dryness. The residue was chromatographed over silica gel $\left(\mathrm{CH}_{2} \mathrm{Cl}_{2}\right)$ to give monoester 2 in 39\% yield as colorless oil. ${ }^{1} \mathrm{H}$ NMR $\left(\mathrm{CDCl}_{3}\right) \delta 7.90(\mathrm{~d}, J=2 \mathrm{~Hz}, 2 \mathrm{H}$, ArH of endcap), $7.62(\mathrm{t}, J=2 \mathrm{~Hz}, 1 \mathrm{H}$, ArH of endcap), $6.83(\mathrm{~s}, 4 \mathrm{H}$, p-phenylene $), 4.50\left(\mathrm{~m}, 2 \mathrm{H}, \mathrm{CH}_{2}\right), 4.10-3.60(\mathrm{~m}$, $14 \mathrm{H}, \mathrm{CH}_{2}$ ), $1.34(\mathrm{~s}, 18 \mathrm{H}, t$-Bu). FT-IR (film) v 3502 $\left(v_{\mathrm{O}-\mathrm{H}}\right), 1716\left(v_{\mathrm{C}=\mathrm{O}}\right) \mathrm{cm}^{-1}$.

Synthesis of Acrylic Acid Ester (3). To a THF

${ }^{\dagger}$ To whom correspondence should be addressed (E-mail: ttakata@polymer.titech.ac.jp). 

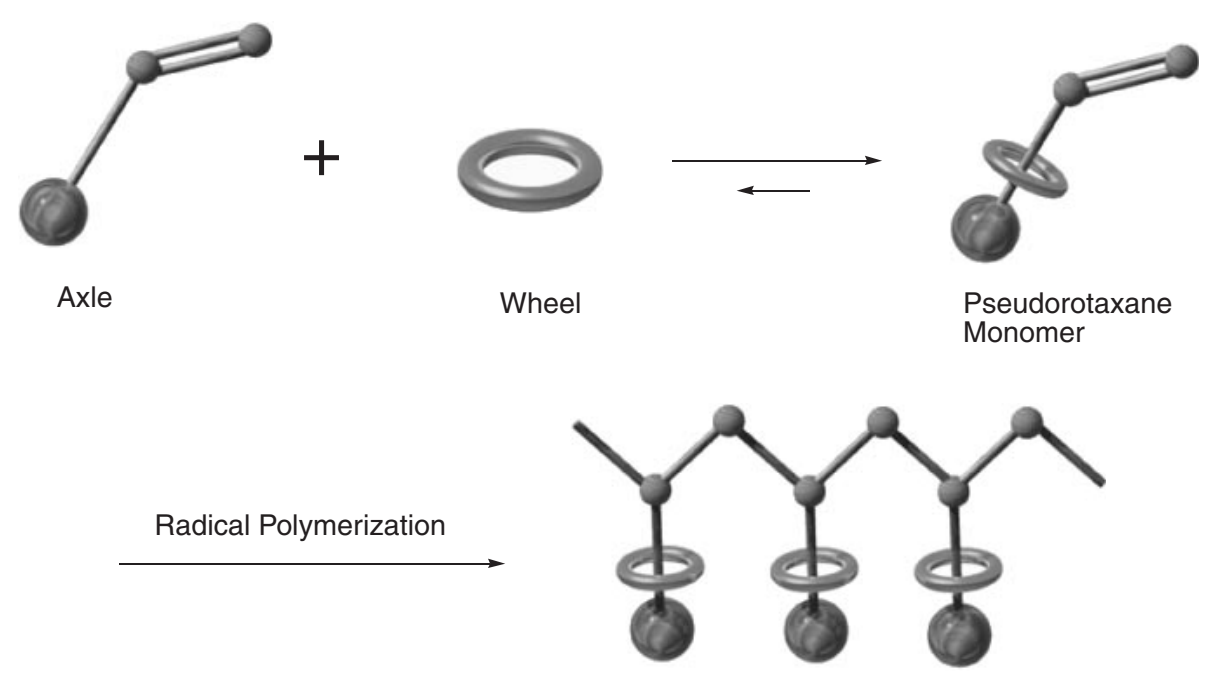

Side-Chain Polyrotaxane

Scheme 1.

$(9.0 \mathrm{~mL})$ solution of monoester $2(0.84 \mathrm{~g}, 1.6 \mathrm{mmol})$ and $\mathrm{Et}_{3} \mathrm{~N}(0.25 \mathrm{~g}, 2.5 \mathrm{mmol})$ was added acryloyl chloride $(0.23 \mathrm{~g}, 2.5 \mathrm{mmol})$. The mixture was stirred for $1 \mathrm{~h}$ at room temperature. The mixture was acidified with $2 \mathrm{M} \mathrm{HCl}(100 \mathrm{~mL})$ and extracted with ether $(100 \mathrm{~mL} \times 1)$. The extract was washed with water $(30 \mathrm{~mL} \times 1)$ and brine $(30 \mathrm{~mL})$, dried $\left(\mathrm{MgSO}_{4}\right)$, and evaporated to dryness. The residue was purified with silica gel chromatography $\left(\mathrm{CH}_{2} \mathrm{Cl}_{2}\right)$ to afford acrylate 3 in $41 \%$ yield as a colorless oil. ${ }^{1} \mathrm{H}$ NMR $\left(\mathrm{CDCl}_{3}\right.$, $270 \mathrm{MHz}) \delta 7.90(\mathrm{~d}, J=2 \mathrm{~Hz}, 2 \mathrm{H}$, ArH of endcap), $7.62(\mathrm{t}, J=2 \mathrm{~Hz}, 1 \mathrm{H}$, ArH of endcap), $6.72(\mathrm{~s}, 4 \mathrm{H}$, p-phenylene), $6.42(\mathrm{dd}, J=17 \mathrm{~Hz}, 2 \mathrm{~Hz}, 1 \mathrm{H}$, $\mathrm{OCOCH}=\mathrm{CH}_{2}($ cis to $\left.\mathrm{C}=\mathrm{O})\right), 6.14(\mathrm{dd}, J=17 \mathrm{~Hz}$, $10 \mathrm{~Hz}, 1 \mathrm{H}, \quad$ OCOC$\left.\underline{\mathrm{H}}=\mathrm{CH}_{2}\right), 5.83(\mathrm{dd}, J=10 \mathrm{~Hz}$, $2 \mathrm{~Hz}, 1 \mathrm{H}, \mathrm{OCOCH}=\mathrm{CH}_{2}$ (trans to $\left.\mathrm{C}=\mathrm{O}\right)$ ), 4.54$4.48\left(\mathrm{~m}, 2 \mathrm{H}, \mathrm{CH}_{2} \mathrm{O}\right), 4.37-4.31\left(\mathrm{~m}, 2 \mathrm{H}, \mathrm{CH}_{2} \mathrm{O}\right)$, 4.13-4.04 (m, 2H, $\left.\mathrm{CH}_{2} \mathrm{O}\right), 3.94-3.78\left(\mathrm{~m}, 2 \mathrm{H}, \mathrm{CH}_{2} \mathrm{O}\right)$, $1.34\left(\mathrm{~s}, 18 \mathrm{H}, t\right.$-Bu). FT-IR (film) $v 1722\left(v_{\mathrm{C}=\mathrm{O}}\right), 1635$ $\left(v_{\mathrm{C}=\mathrm{C}}\right) \mathrm{cm}^{-1}$.

A Typical Procedure for Polymerization of Pseudorotaxane Monomer $\left(\boldsymbol{6} \cdot P F_{6}\right)$. A mixture of acrylate 3 (278 $\mathrm{mg}, 0.500 \mathrm{mmol}$ ), cyclophane $4 \cdot \mathrm{PF}_{6}{ }^{11}$ (550 mg, $0.500 \mathrm{mmol})$, AIBN (10 mg, $0.06 \mathrm{mmol})$, and acetonitrile $(5.0 \mathrm{~mL})$ was heated in a sealed tube under Ar atmosphere at $70^{\circ} \mathrm{C}$ for $20 \mathrm{~h}$. The mixture was allowed to cool to room temperature and evaporated to dryness to give a mixture of polyrotaxane $\left(\mathbf{6} \cdot \mathrm{PF}_{6}\right)$ and unincorporated wheel $\left(\mathbf{4} \cdot \mathrm{PF}_{6}\right)$ as a red solid. ${ }^{1} \mathrm{H}$ NMR $\left(\right.$ DMSO- $\left.d_{6}, 270 \mathrm{MHz}\right) \delta 9.4\left(\mathrm{~d}, J=6 \mathrm{~Hz}, 8 \mathrm{H}, \mathrm{H}_{\alpha}\right.$ of 4. $\mathrm{PF}_{6}$ ), 9.2 (br s, $8 \mathrm{H}, \mathrm{H}_{\beta}$ of wheel), 8.7 (d, $J=6 \mathrm{~Hz}, 8 \mathrm{H}, \mathrm{H}_{\beta}$ of $\mathbf{4} \cdot \mathrm{PF}_{6}$ ), 8.3 (br s, $8 \mathrm{H}, \mathrm{H}_{\beta}$ of wheel), 7.8 (br s, 8H, p-phenylene of wheel), 7.7 (s, $8 \mathrm{H}, p$-phenylene of $\left.4 \cdot \mathrm{PF}_{6}\right), 7.7-7.5(\mathrm{~m}, 3 \mathrm{H}, \mathrm{ArH}$ of endcap), 6.7 (br s, $8 \mathrm{H}, p$-phenylene of axle), 5.8 (br s, $8 \mathrm{H}, \mathrm{CH}_{2}$ of wheel), $5.7\left(\mathrm{~s}, 8 \mathrm{H}, \mathrm{CH}_{2}\right.$ of wheel), 4.5-3.0 (m, $16 \mathrm{H}, \mathrm{CH}_{2} \mathrm{O}$ of axle), 2.5 (br s, $1 \mathrm{H}, \mathrm{CH}$ of the main chain), 1.3-1.0 (br s, 20H, $t$-Bu and $\mathrm{CH}_{2}$ of the main chain). From the ${ }^{1} \mathrm{H}$ NMR spectrum, the $R$ value (the incorporation ratio of rotaxane unit) was determined to be $10 \%$. FT-IR (KBr) v 2965, 1718, 1637, 1508, 1450, 1238, 1153, $840\left(\mathrm{PF}_{6}\right), 781$, 642, $557\left(\mathrm{PF}_{6}\right), 530 \mathrm{~cm}^{-1}$.

Isolation of Polyrotaxane $(6 \cdot \mathrm{Cl})$. A mixture of 6. $\mathrm{PF}_{6}$ and $\mathbf{4} \cdot \mathrm{PF}_{6}$ in $\mathrm{H}_{2} \mathrm{O}$-sat. $\mathrm{NH}_{4} \mathrm{Claq}-\mathrm{MeOH}(1 / 1 /$ $2(\mathrm{v} / \mathrm{v} / \mathrm{v}))$ was refluxed for $1 \mathrm{~d}$. The mixture was cooled to room temperature and filtered to give polyrotaxane $(\mathbf{6} \cdot \mathrm{Cl})$ as a red solid. ${ }^{1} \mathrm{H}$ NMR (DMSO- $d_{6}$, $270 \mathrm{MHz})$ : see Figure 2(v). FT-IR (KBr) v 2960, $1722,1631,1508,1454,1363,1238,1132,1062$, $946,827,773,707,541,526 \mathrm{~cm}^{-1}$.

\section{RESULTS AND DISCUSSION}

\section{Synthesis of Axle and Wheel Components}

Axle having an acryl end (3) was synthesized as illustrated in Scheme 2. Monoesterification of $\mathbf{1}$ with 3,5-di-t-butylbenzoyl chloride lead to the corresponding monoester (2), ${ }^{11}$ which was converted to 3 by acylation with acryloyl chloride. Paraquat-type tetracationic macrocycle $\left(4 \cdot \mathrm{PF}_{6}\right)$ as the wheel component was prepared according to the Stoddart's method. ${ }^{11}$

\section{Pseudorotaxane Monomer}

The pseudorotaxane monomer $\left(\mathbf{5} \cdot \mathrm{PF}_{6}\right)$ was prepared in situ by adding an equimolar amount of $\mathbf{3}$ to a $\mathrm{CD}_{3} \mathrm{CN}$ solution of $\mathbf{4} \cdot \mathrm{PF}_{6}$. Upon addition of $\mathbf{3}$, the ${ }^{1} \mathrm{H}$ NMR signals of aromatic protons $\mathrm{a}$ and $\mathrm{b}$ in 4. $\mathrm{PF}_{6}$ exhibited upfield shifts $(c a .-0.02 \mathrm{ppm}$ and ca. $-0.20 \mathrm{ppm}$ for a and $\mathrm{b}$, respectively), while that 


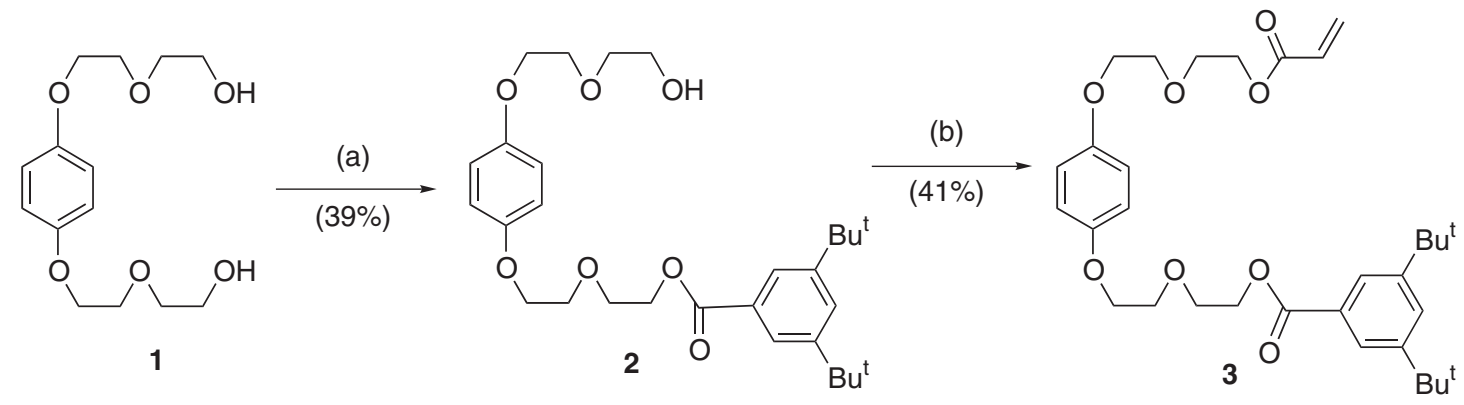

Scheme 2. Synthesis of Axle (3). Reagents and conditions: (a) 3,5-bis(di-t-butyl)benzoyl chloride, $\mathrm{Et}_{3} \mathrm{~N}, \mathrm{CH}_{2} \mathrm{Cl}_{2}, \mathrm{rt}$; (b) acryloyl chloride, $\mathrm{Et}_{3} \mathrm{~N}, \mathrm{CH}_{2} \mathrm{Cl}_{2}$, rt.

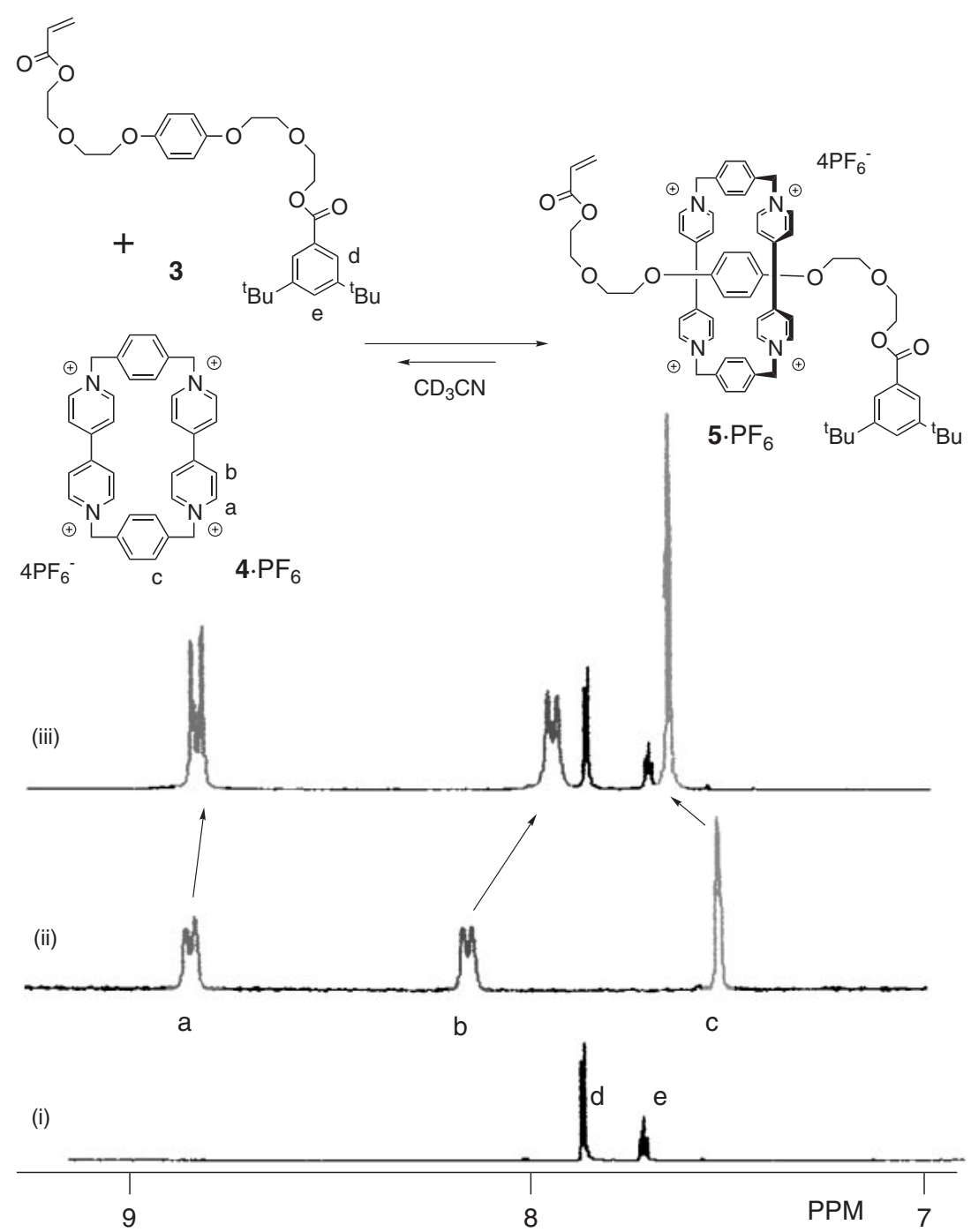

Figure 1. Partial ${ }^{1} \mathrm{H}$ NMR spectra $\left(270 \mathrm{MHz}, \mathrm{CD}_{3} \mathrm{CN}, 298 \mathrm{~K}\right)$ of (i) axle (3), (ii) wheel $\left(\mathbf{4} \cdot \mathrm{PF}_{6}\right)$, and (iii) pseudorotaxane monomer $\left(5 \cdot \mathrm{PF}_{6}\right)$.

of $\mathrm{c}$ in $4 \cdot \mathrm{PF}_{6}$ showed a downfield shift ( $c a$. $+0.14 \mathrm{ppm}$ ), as shown in Figure 1. These behaviors were consistent with the ${ }^{1} \mathrm{H}$ NMR spectral change between the pseudorotaxane prepared in situ from $\mathbf{1}$ and $4 \cdot \mathrm{PF}_{6}$ in $\mathrm{CD}_{3} \mathrm{CN}$, which was reported by Stoddart et $a l .{ }^{11}$ In accordance with these changes, the color change of the solution from colorless to brownish or- ange was observed. This is attributed to the charge transfer complex formation between the bipyridinium units and the hydroquinol ring.

\section{Radical Polymerization of 5 $P F_{6}$}

Since the pseudorotaxane monomer $\left(\mathbf{5} \cdot \mathrm{PF}_{6}\right)$ exists in equilibrium between the axle monomer (3) and 

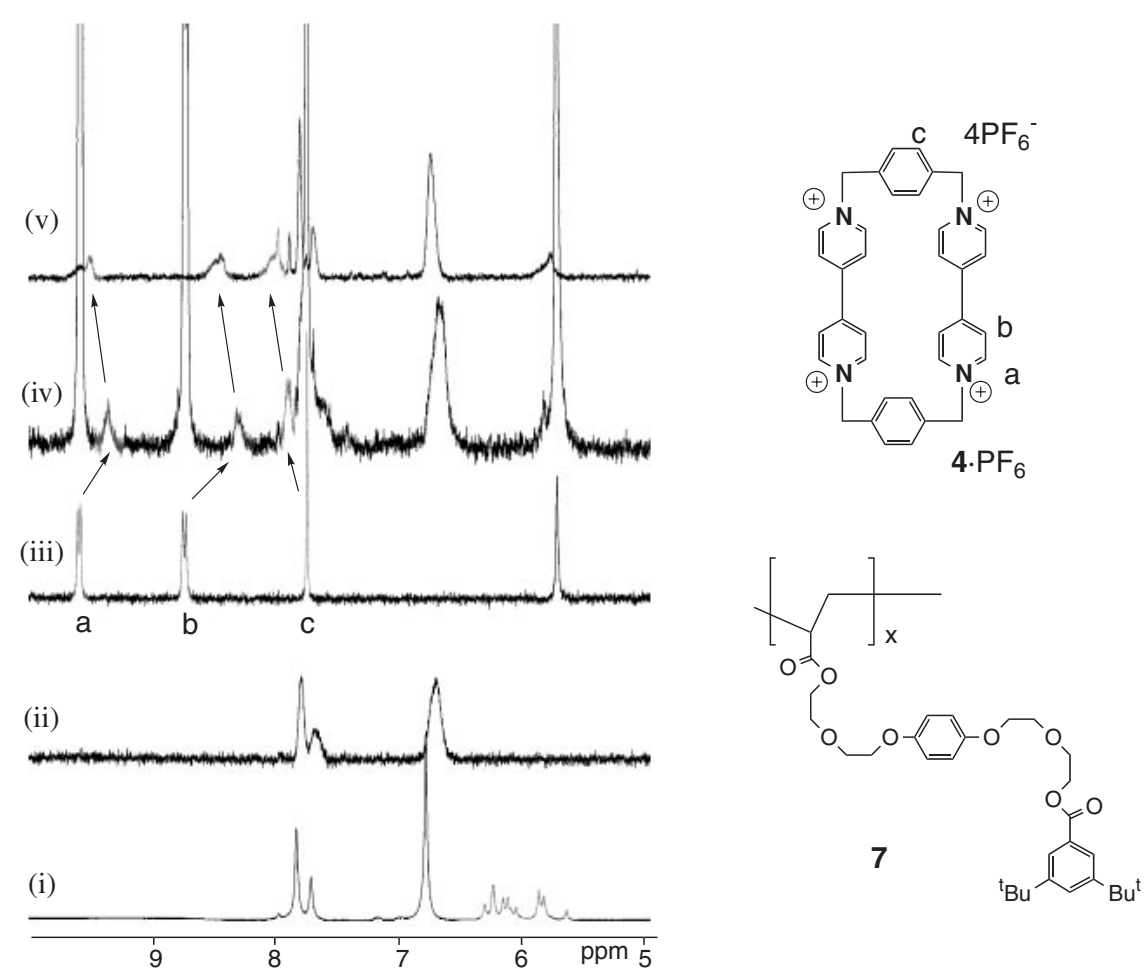

Figure 2. Partial ${ }^{1} \mathrm{H}$ NMR spectra (DMSO- $\left.d_{6}, 298 \mathrm{~K}, 270 \mathrm{MHz}\right)$ of (i) axle (3), (ii) poly(axle) (7), (iii) wheel (4· $\left.\mathrm{PF}_{6}\right)$, (iv) a mixture of polyrotaxane $\left(\mathbf{6} \cdot \mathrm{PF}_{6}\right)$ and wheel $\left(\mathbf{4} \cdot \mathrm{PF}_{6}\right)$, and $(\mathrm{v})$ polyrotaxane $(\mathbf{6} \cdot \mathrm{Cl})$.

4. $\mathrm{PF}_{6}$, it is conceivable that $\mathbf{5} \cdot \mathrm{PF}_{6}$ copolymerizes with 3 (Scheme 3). In particular, the polymerizability difference between them may largely affect the composition of the copolymers being formed.

The radical polymerization of $\mathbf{5} \cdot \mathrm{PF}_{6}$ was carried out by heating an equimolar mixture of 3 and $\mathbf{4} \cdot \mathrm{PF}_{6}$ in acetonitrile for $20 \mathrm{~h}$. Evaporation of the reaction mixture gave a mixture of polyrotaxane $\mathbf{6} \cdot \mathrm{PF}_{6}$ and $4 \cdot \mathrm{PF}_{6}$ (recovered) as a red solid. The incorporation ratio of the rotaxane unit $(R$ value, $R=100 y /(x+y)$ ) was determined to be $10 \%$ by its ${ }^{1} \mathrm{H}$ NMR spectrum in DMSO- $d_{6}$ (Figure 2). Since the isolation of $\mathbf{6} \cdot \mathrm{PF}_{6}$ by precipitation was unsuccessful, counter anion exchange from hexafluorophosphate to chloride was conducted by refluxing the product mixture in $\mathrm{H}_{2} \mathrm{O}-$ sat. $\mathrm{NH}_{4}$ Claq. $-\mathrm{MeOH}(1 / 1 / 2 \quad(\mathrm{v} / \mathrm{v} / \mathrm{v}))$ for $24 \mathrm{~h}$ (Scheme 3 ). $\mathbf{6} \cdot \mathrm{Cl}$ was isolated in $28 \%$ yield by filtration, because $4 \cdot \mathrm{Cl}$ was soluble in water while $\mathbf{6} \cdot \mathrm{Cl}$ was not. $\mathbf{6} \cdot \mathrm{Cl}$ thus obtained was characterized by ${ }^{1} \mathrm{H}$ NMR, IR, and GPC. The absorption bands at 840 and $557 \mathrm{~cm}^{-1}$ due to $\mathrm{PF}_{6}$ anion completely disappeared in the IR spectrum of $\mathbf{6} \cdot \mathrm{Cl}$. The incorporation ratio ( $R$ value) of $\mathbf{6} \cdot \mathrm{Cl}$ was determined to be $12 \%$ by its ${ }^{1} \mathrm{H}$ NMR spectrum in DMSO- $d_{6}$ (Figure 2). The molecular weight of $\mathbf{6} \cdot \mathrm{Cl}$ was estimated to be an $M_{\mathrm{n}}$ of 5,000 $\left(M_{\mathrm{w}} / M_{\mathrm{n}}=40, \mathrm{CHCl}_{3}\right.$, PSt standards $)$ by GPC.

The low composition of the rotaxane unit can be accounted for by the polymerization rate difference between the acrylate 3 and the pseudorotaxane monomer $\mathbf{5} \cdot \mathrm{PF}_{6}$ formed in situ in the competitive condition where these two species are in existence in an equilibrium (Scheme 3). Stoddart reported that association constant $\left(K_{\mathrm{a}}\right)$ for 1:1 complexation between a 1,4-dialkoxybenzene similar to $\mathbf{1}$ and the wheel $\mathbf{4}$ was $2220 \mathrm{M}^{-1}$ (acetonitrile, $25^{\circ} \mathrm{C}$ ). ${ }^{11}$ In this case, the complexation ratio is calculated to be $94 \%$. Since in the present study the polymerization is carried out at $70^{\circ} \mathrm{C}$, the ratio would be lower than that. However, the low composition is difficult to explain only from the equilibrium because the complexation ratio is $80 \%$ even when $K_{\mathrm{a}}=200$. Therefore, it seems reasonable that the polymerization rate of $\mathbf{3}$ without the wheel is much larger than that of the pseudorotaxane monomer $\mathbf{5} \cdot \mathrm{PF}_{6}$.

Various solvents were examined in the radical polymerization of $\mathbf{5} \cdot \mathrm{PF}_{6}$ and the $R$ value was determined by ${ }^{1} \mathrm{H}$ NMR (Table I). Methanol, THF, acetone, and chloroform resulted in $R=0$, that is, no $4 \cdot \mathrm{PF}_{6}$ was incorporated in the polymer side chain at all (entries 15). These results are attributed to the fact that $4 \cdot \mathrm{PF}_{6}$ is highly insoluble in those solvents so that no $\mathbf{5} \cdot \mathrm{PF}_{6}$ was formed. Almost same $R$ values were observed for DMSO (9\%) and acetonitrile (10\%) (entries 5 and 6). The $R$ value decrease was observed in the polymerization at a lower feed concentration of $0.01 \mathrm{M}$ (entry 7) which leads to the lowered ratio of the pseudorotaxane formation. Increasing the feed 

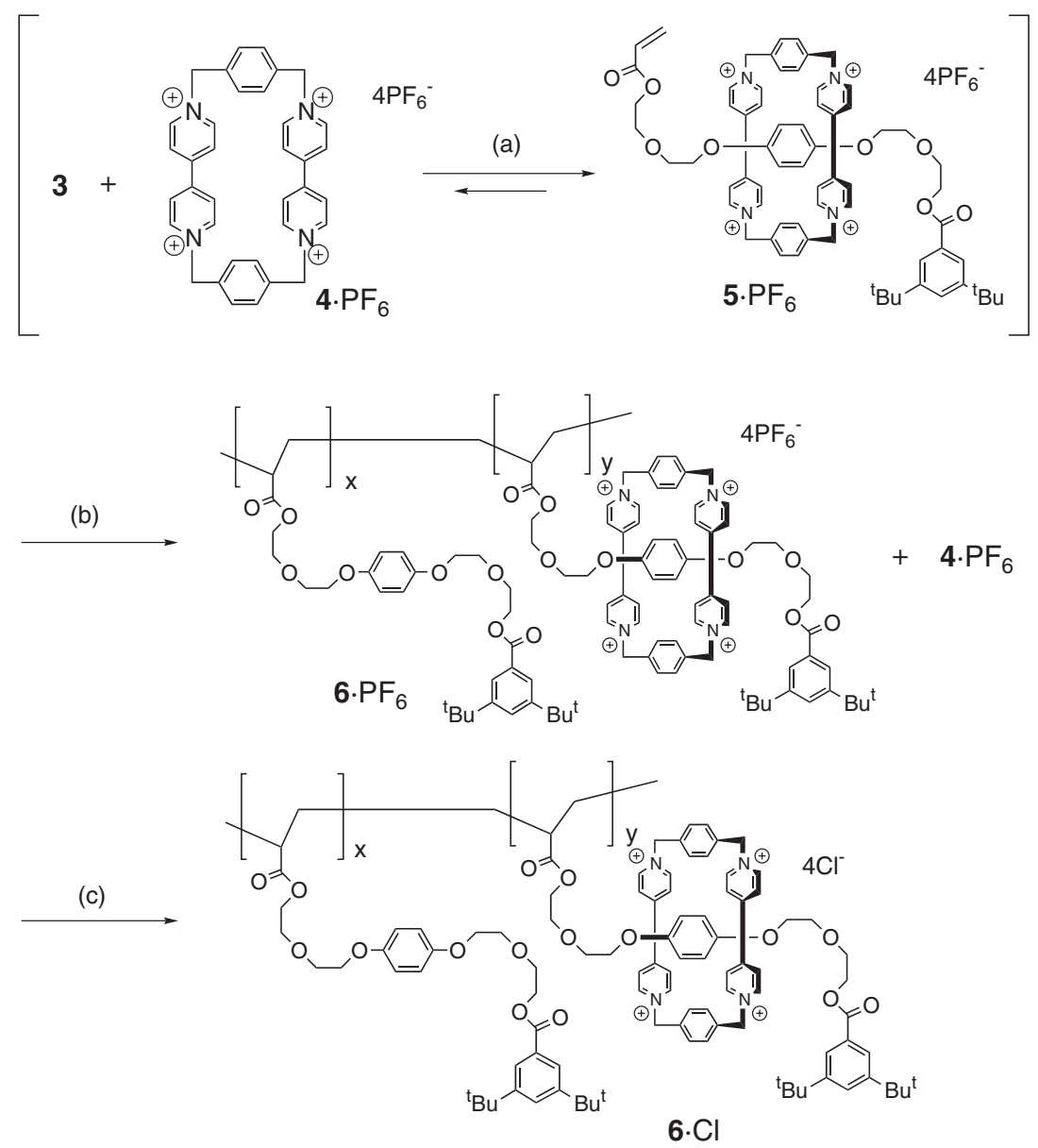

Scheme 3. Synthesis of pseudorotaxane monomer $\left(\mathbf{5} \cdot \mathrm{PF}_{6}\right)$ and side-chain polyrotaxane $\left(6 \cdot \mathrm{PF}_{6}\right)$. Reagents and conditions: $\left(\right.$ a) $\mathrm{CH}_{3} \mathrm{CN}$ (0.10 M), rt; (b) AIBN (10 mol\%), $70^{\circ} \mathrm{C}, 20 \mathrm{~h}$; (c) $\mathrm{H}_{2} \mathrm{O}-$ sat. $\mathrm{NH}_{4}$ Claq-MeOH $(1 / 1 / 2)$, reflux, $24 \mathrm{~h}$.

Table I. Effects of solvent and concentration on the incorporation ratio

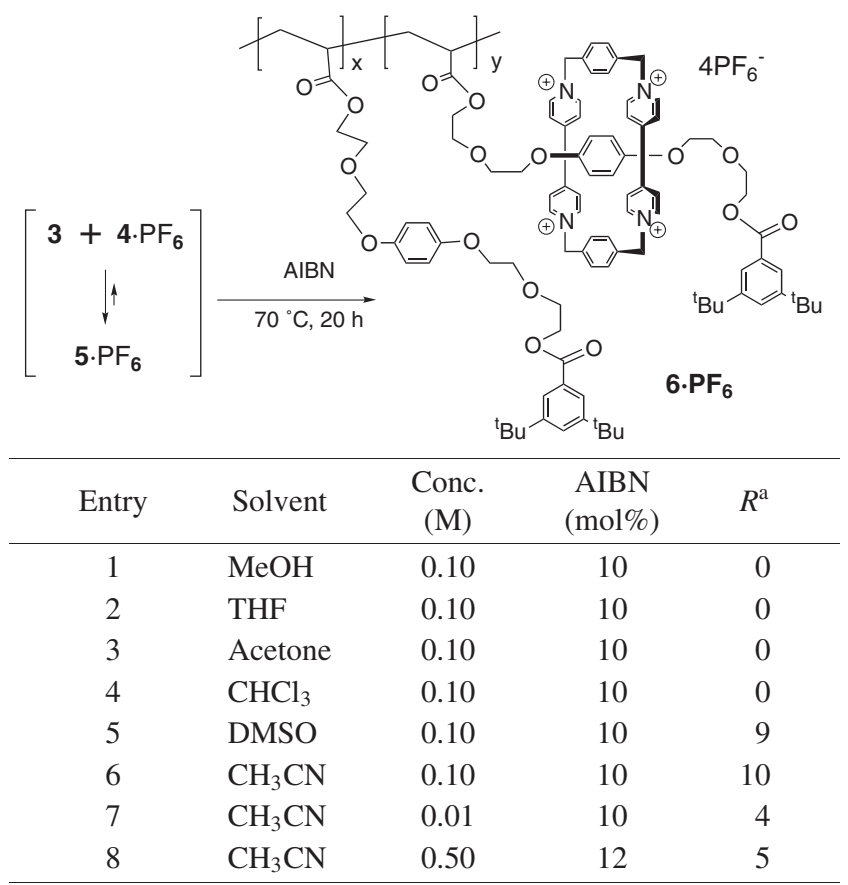

${ }^{\mathrm{a}}$ Incorporation ratio of the rotaxane units, $100 y /(x+y)$, was determined by ${ }^{1} \mathrm{H}$ NMR. concentration up to $0.50 \mathrm{M}$ failed to enhance the $R$ value, because a certain amount of $\mathbf{4} \cdot \mathrm{PF}_{6}$ remained insoluble during the polymerization (entry 8 ). The $R$ value decrease at high concentration can be explained by the prevention of the association to $\mathbf{5} \cdot \mathrm{PF}_{6}$ due to the presence of highly polar compound $\mathbf{4} \cdot \mathrm{PF}_{6}$ at high concentration. Thus, use of the solvents that could dissolve $\mathbf{4} \cdot \mathrm{PF}_{6}$ is indispensable to get the polyrotaxane $\left(\mathbf{6} \cdot \mathrm{PF}_{6}\right)$, while polarity control of the whole system should be taken into consideration.

In summary, a new pseudorotaxane monomer 5. $\mathrm{PF}_{6}$ has been designed based on the paraquat-type tetracationic macrocycle-hydroquinol motif. The radical polymerization of $\mathbf{5} \cdot \mathrm{PF}_{6}$ yielded the corresponding side-chain type polyrotaxane with $R$ value up to $c a$. $10 \%$. The $R$ value highly depends on the solubility of the tetracationic macrocycle to the solvent and probably on the polarity of the whole polymerization system.

\section{REFERENCES}

1. a) G. Schill, "Catenanes, Rotaxanes, and Knots," Academic Press, New York, N.Y., 1971. 
b) J.-C. Chambron and J.-P. Sauvage, Top. Curr. Chem., 165, 131 (1993).

c) D. B. Amabilino and J. F. Stoddart, Chem. Rev., 95, 2725 (1995).

d) E. G. Gillard, F. M. Raymo, and J. F. Stoddart, Chem.Eur. J., 3, 1933 (1997).

e) R. Jäger and F. Vögtle, Angew. Chem., Int. Ed., 36, 930 (1997).

f) J.-P. Sauvage and C. O. Dietrich-Buchecker, Ed., "Molecular Catenanes, Rotaxanes and Knots," John Wiley \& Sons, New York, N.Y., 1999.

g) T. Takata, N. Kihara, and Y. Furusho, Adv. Polym. Sci., in press.

2. a) T. Takata, Y. Furusho, and J. Shoji, Chem. Lett., 881 (1997).

b) N. Watanabe, Y. Furusho, N. Kihara, T. Takata, K. Kinbara, and K. Saigo, Chem. Lett., 915 (1999).

c) Y. Furusho, J. Shoji, N. Watanabe, N. Kihara, T. Adachi, and T. Takata, Bull. Chem. Soc. Jpn., 74, 139 (2001).

d) N. Watanabe, Y. Furusho, N. Kihara, T. Takata, K. Kinbara, and K. Saigo, Bull. Chem. Soc. Jpn., 74, 149 (2001).

3. a) Y. Geerts, D. Muscat, and K. Müllen, Macromol. Chem. Phys., 196, 3425 (1995).

b) J.-L. Weidemann, J.-M. Kern, J.-P. Sauvage, Y. Geerts, D. Muscat, and K. Müllen, Chem. Commun., 1243 (1996). c) D. Muscat, A. Witte, W. Köhler, K. Müllen, and Y. Geerts, Macromol. Rapid Commun., 18, 233 (1997).

d) D. Muscat, W. Köhler, H. J. Räder, K. Martin, S. Mullins, B. Müller, K. Müllen, and Y. Geerts, Macromolecules, 32, 1737 (1999). e) J.-L. Weidemann, J.-M. Kern, J.-P. Sauvage, D. Muscat, S. Mullins, H. J. Räder, K. Martin, and Y. Geerts, Chem.Eur. J., 5, 1841 (1999).

4. K. Yoshida, T. Shimomura, K. Ito, and R. Hayakawa, Langmuir, 15, 910 (1999).

5. Y. Okumura and K. Ito, Adv. Mater., 13, 485 (2001).

6. T. Oku, Y. Furusho, and T. Takata, Angew. Chem., Int. Ed., 43, 966 (2004).

7. T. Oku, Y. Furusho, and T. Takata, J. Polym. Sci., Part A: Polym. Chem., 41, 119 (2003).

8. a) O. Noll and H. Ritter, Macromol. Chem. Phys., 199, 791 (1998).

b) J. Jeromin and H. Ritter, Macromol. Rapid Commun., 19, 377 (1998).

c) J. Jeromin and H. Ritter, Macromolecules, 32, 5236 (1999).

9. a) T. Takata and N. Kihara, Rev. Heteroatom Chem., 22, 197 (2000).

b) N. Kihara and T. Takata, J. Synth. Org. Chem. Jpn., 59, 206 (2001).

10. a) T. Takata, H. Kawasaki, S. Asai, N. Kihara, and Y. Furusho, Chem. Lett., 111 (1999).

b) T. Takata, H. Kawasaki, N. Kihara, and Y. Furusho, Macromolecules, 34, 5449 (2001).

11. P. L. Anelli, P. R. Ashton, R. Ballardini, V. Balzani, M. Delgado, M. T. Gandolfi, T. T. Goodnow, A. E. Kaifer, D. Philp, M. Pietraszkiewicz, L. Prodi, M. V. Reddington, A. M. Z. Slawin, N. Spencer, J. F. Stoddart, C. Vincent, and D. J. Williams, J. Am. Chem. Soc., 114, 193 (1992).

12. Y. Furusho, T. Oku, T. Hasegawa, A. Tsuboi, N. Kihara, and T. Takata, Chem.-Eur. J., 9, 2895 (2003). 